\title{
\$14.5-Billion Per Year and Counting: Canadian Gambling Statistics
}

\author{
Rhys Stevens \\ This non-peer reviewed entry is published as part of the Critical Gambling Studies Blog. Visit an interactive \\ version of this blog at: https://criticalgamblingstudies.blogspot.com/2021/06/145-billion-per-year-and- \\ counting.html
}

\begin{abstract}
Ask any gambler how much money they spend on gambling in a typical year and you'll almost certainly see a quizzical look appear on their face. Individuals are frequently reluctant to disclose such information and those that do typically find it difficult to recall the specifics of their gambling spending. Gamblers who are willing and able to answer might also need some clarification since the question could be referring to either the cumulative amount of dollars gambled or the net dollar figure gambled after accounting for wins and losses ${ }^{1}$. But what if, instead of asking individual gamblers about their spending, one was attempting to determine gambling spending for the entire country of Canada including provinces and territories... are these figures even available? Are provincial and territorial gambling regulators and operators forthcoming with this information? The short answer is that, yes, it is indeed possible to determine a figure for Canada's net commercial gambling revenue using available data ${ }^{2}$. In this article, I'll describe my rationale for documenting available Canadian gambling statistics, methods employed, and challenges encountered. A selection of charts is interspersed throughout to illustrate key gambling statistics using examples from the Canadian Gambling Statistics (1970-2020) online database which was created to house these collected statistics and make them publicly accessible.
\end{abstract}

\section{Rationale for Documenting Canadian Gambling Statistics}

The main purpose of gathering figures about gambling in Canada was to provide background information and context for a comprehensive scholarly research investigation of Gambling and Problem Gambling in Canada: A National Study ${ }^{3}$ undertaken between 2018 and 2020. As a member of the research team, my specific role was to document the types of gambling that are legal in each province, revenue generation, revenue distribution, and responsible gambling activities and initiatives. The end product of this work was the Canadian Gambling Statistics (1970-2020) online database which contains 35 separate interactive visualizations. In addition, a series of ten spreadsheets was created to provide background information about Canadian gambling legislation, prevalence, revenues, formats, casino locations, online websites, player cards programs, responsible gambling and a history of events by province.

\footnotetext{
1 To learn about these intricacies, see Wood \& Williams (2007) ‘How Much Money Do You Spend on Gambling?' The Comparative Validity of Question Wordings Used to Assess Gambling Expenditure and Auer \& Griffiths (2017) $\underline{\text { Self-Reported }}$ Losses Versus Actual Losses in Online Gambling: An Empirical Study.

${ }^{2}$ Calculate at $\$ 14.51$-billion in 2019 or about $\$ 500$ per Canadian adult (18+ years of age) - for details, see Figure 1.

${ }^{3}$ Funding for the study provided by the Alberta Gambling Research Institute, Canadian Centre on Substance Use and Addiction, Canadian Consortium for Gambling Research and Gambling Research Exchange Ontario. Members of the research team include: Dr. Robert Williams, Dr. Carrie Leonard, Dr. Yale D. Belanger, Dr. Darren R. Christensen, Dr. Nady A. el-Guebaly, Dr. David C. Hodgins, Dr. Daniel S. McGrath, Dr. Fiona Nicoll, Dr. Garry J. Smith, Mr. Rhys M. G. Stevens, and Dr. Darrel Manitowabi.
} 


\section{Critical Gambling Studies Blog}

Figure 1: Canada Commercial Gambling Net Revenue \& Net Income by Province/Territory by Year [2019]

Canada Commercial Gambling Net Revenue \& Net Income by Province/Territory by Year
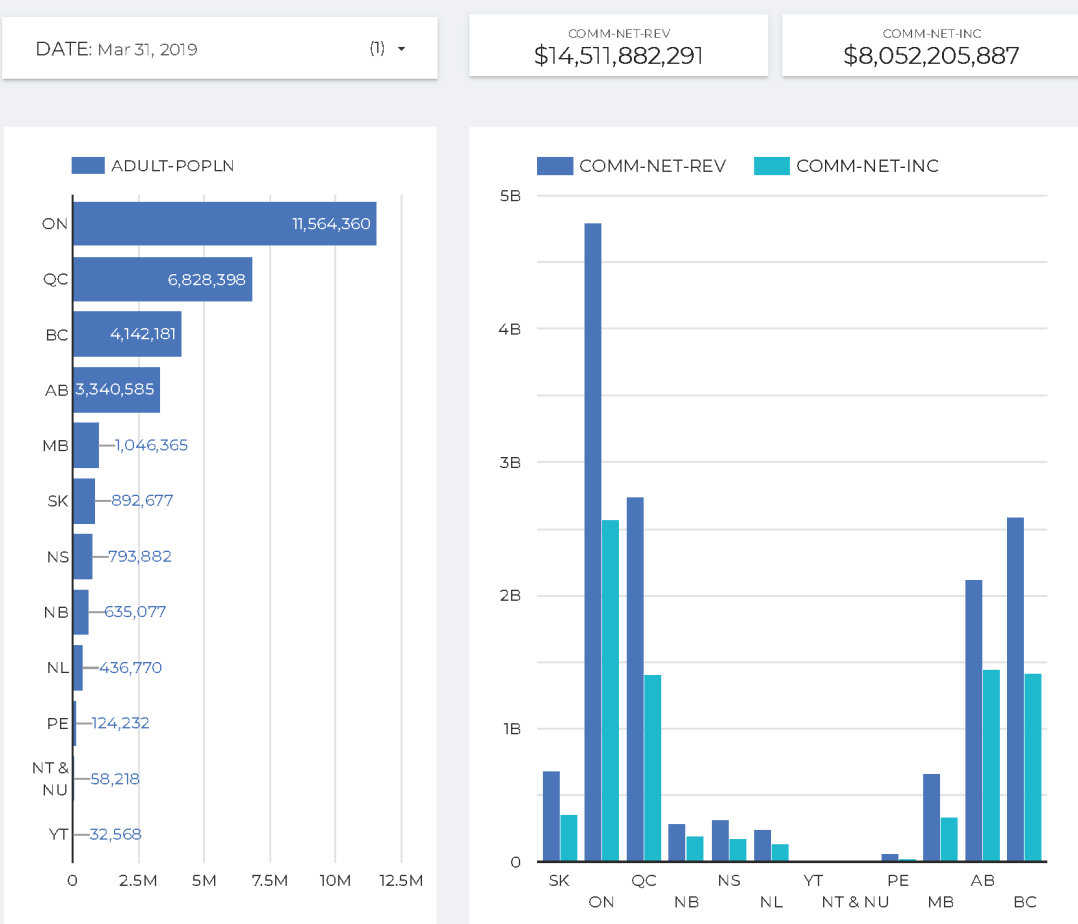

Use the 'DATE' drop-down menu to select a particular fiscal year. for all provinces / all time periods; Adult Population figures are for adults (age 18+); figures unavailable prior to 1972. Source: Source: Statistics Canada. Table 1710-0005-01 Population estimates on July 1st, by age and sex. DOI: https://doi.org/10.25318/1710000501-eng.

This interactive chart can be accessed from the Canadian Gambling Statistics (1970-2020) online database: NET-REV / NET-INC by Yr. Use the DATE drop-down menu in the upper left to select a different year or years of interest. 


\section{Critical Gambling Studies Blog}

Figure 2: Canada Commercial Gambling Net Revenue Per Adult (18+) by Province [2009-2020]

Canada Commercial Gambling Net Revenue Per Adult (18+) by Province [2009-2020]

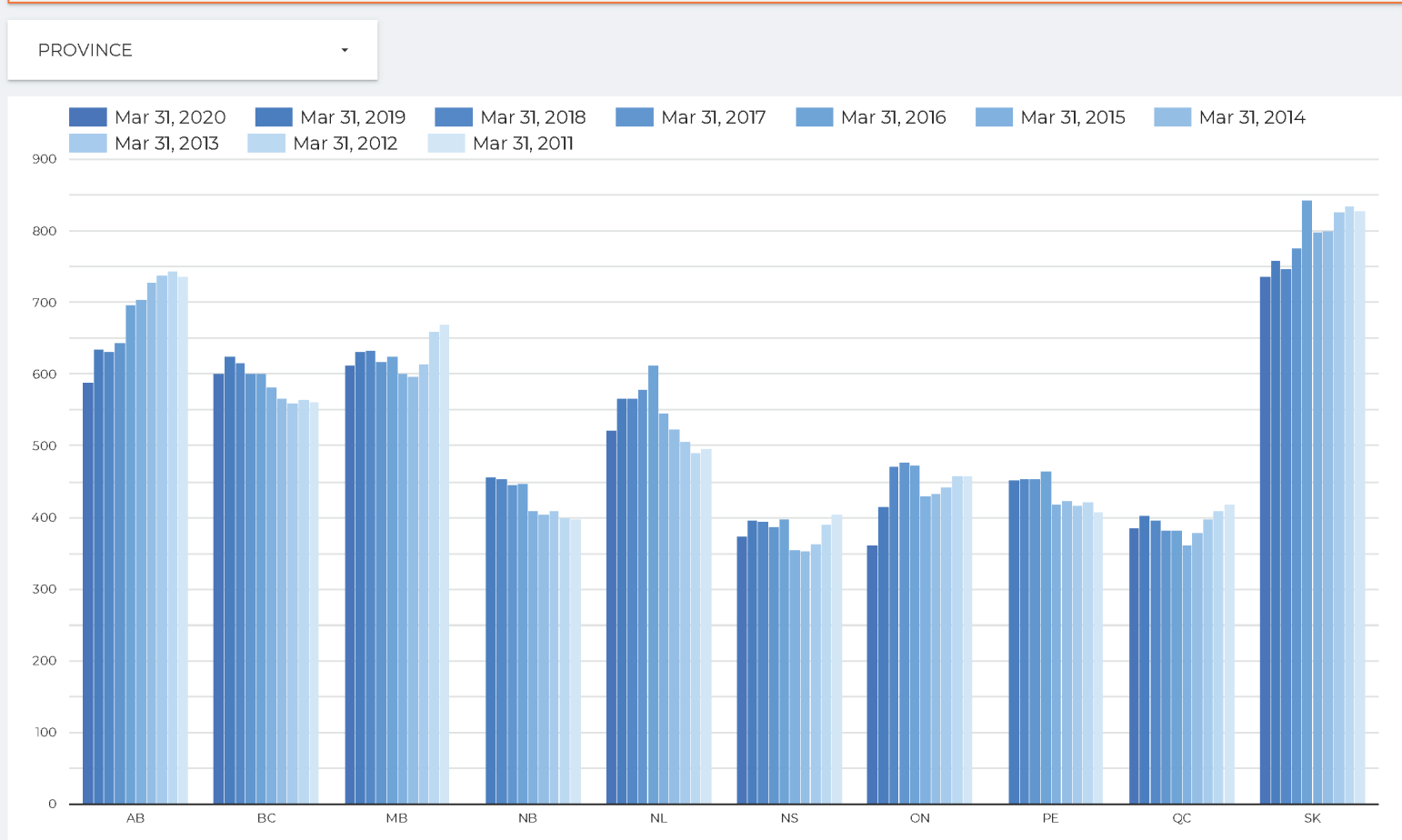

COMM-NET-REV figure for ON from 2017/18+ includes deduction of gaming service provider fees.

This interactive chart can be accessed from the Canadian Gambling Statistics (1970-2020) online database: NET-REV per Adult by Prov. Use the PROVINCE drop-down menu in the upper left to select a province or provinces of interest.

\section{Past Efforts to Collect Canadian Gambling Statistics and Related Information}

As one might imagine, there have been previous initiatives that have comprehensively gathered information about gambling in Canada. A few of the more recent and notable examples of publicly available materials have included:

- Cardus Institute Series on Gambling [Cardus Institute Work and Economics Series] In 2020, Cardus, a non-partisan, faith-based think tank, released a series of publications about gambling in British Columbia, Alberta, Ontario and Atlantic Canada. Reports were co-authored by Brian Dijkema and Johanna Wolfurt and include extensive figures and graphs created using collected gambling statistics.

- Canadian Gambling Digest [Canadian Partnership for Responsible Gambling] The Digest was produced annually between years 2002/03 and 2016/17. It provided comprehensive statistics about gambling in Canada as well as information about responsible gambling initiatives. 
- Economic Benefits of the Canadian Gambling Industry [Canadian Gaming Association] The Canadian Gaming Association commissioned reports in 2019, 2011, and 2008 which detailed the economic impacts of the Canadian gambling industry. Reports were authored by HLT Advisory Inc. and contain statistical data from provincial lottery and gaming corporations, regulators and related entities.

- Statistics Canada [Perspectives on Labour and Income]

Perspectives on Labour and Income, discontinued in 2012, was a Statistics Canada periodical that occasionally featured articles about gambling (including statistics). Issues with gambling content were authored by Katherine Marshall and included September-2011, August-2010, July-2009, September2008, and May-2007.

- Canada West Foundation [Gambling in Canada Project]

The Canada West Foundation (CWF) undertook a three-year long study of gambling in Canada from 1998-2001. This investigation was led by Mark Anielski and it included the collection of gambling statistics reported in Gambling in Canada 2001 as well as in Gambling in Canada 2005: Statistics and Context.

Figure 3: Canada Commercial Gambling Net Revenue by Source by Year [1970-2019]

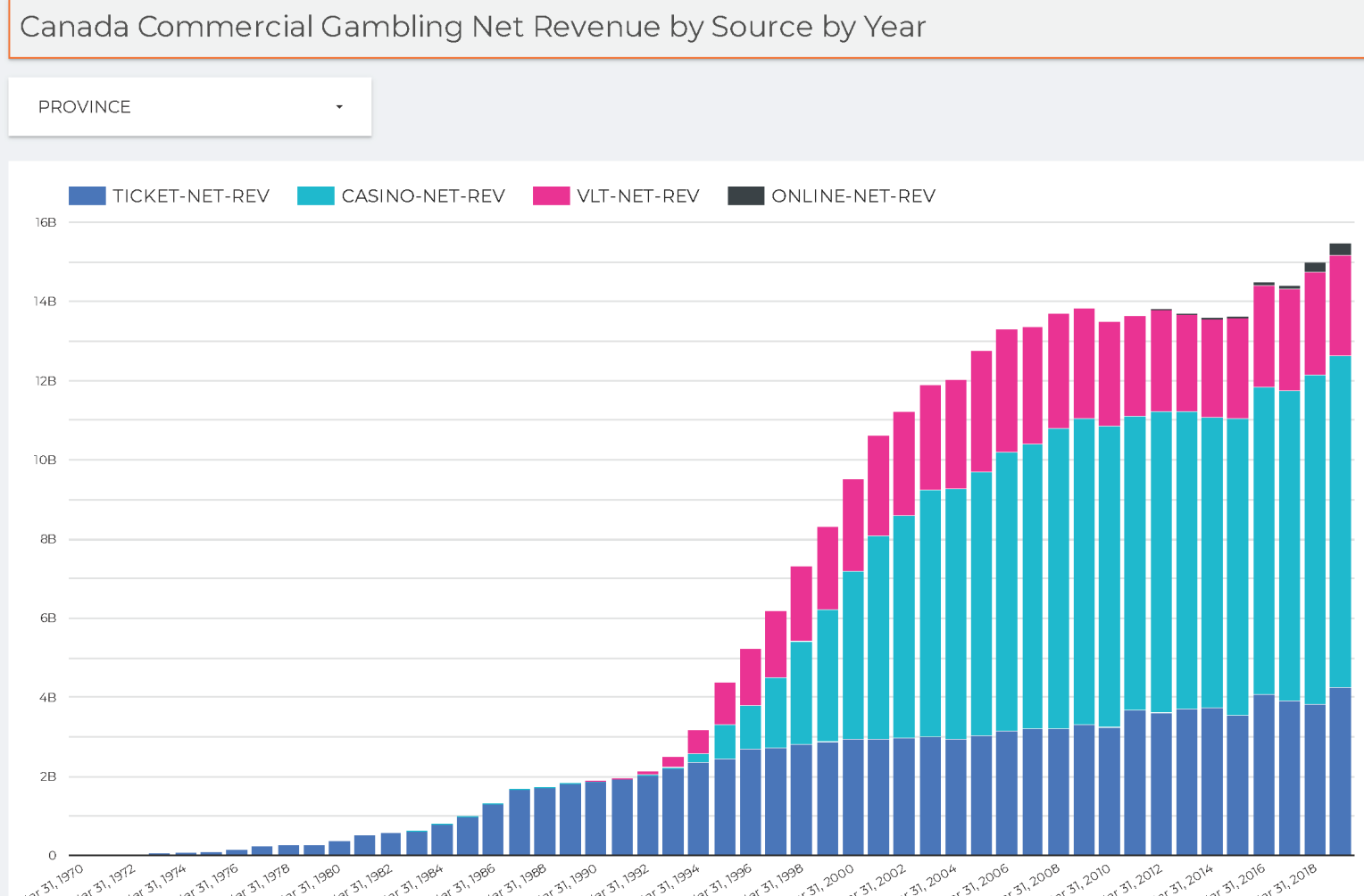

CASINO-NET-REV figure for ON from 2017/18+ excludes deduction of gaming service provider fees (making it comparable with previous years); Only ON, BC, QC separately report ONLINE-NET-REV; Figures for not available for all provinces/all time periods. Aggregated provincial net revenue totals by gambling format do not equal COMM-NET-REV due to other income \& expenses included in provincial reporting.

This interactive chart can be accessed from the Canadian Gambling Statistics (1970-2020) online database: NET-REV by Source by Yr. Use the PROVINCE drop-down menu in the upper left to select a province or provinces of interest. 
Figure 4: Provincial/Territorial Commercial Gambling Net Revenue by Source by Single Year [2019]

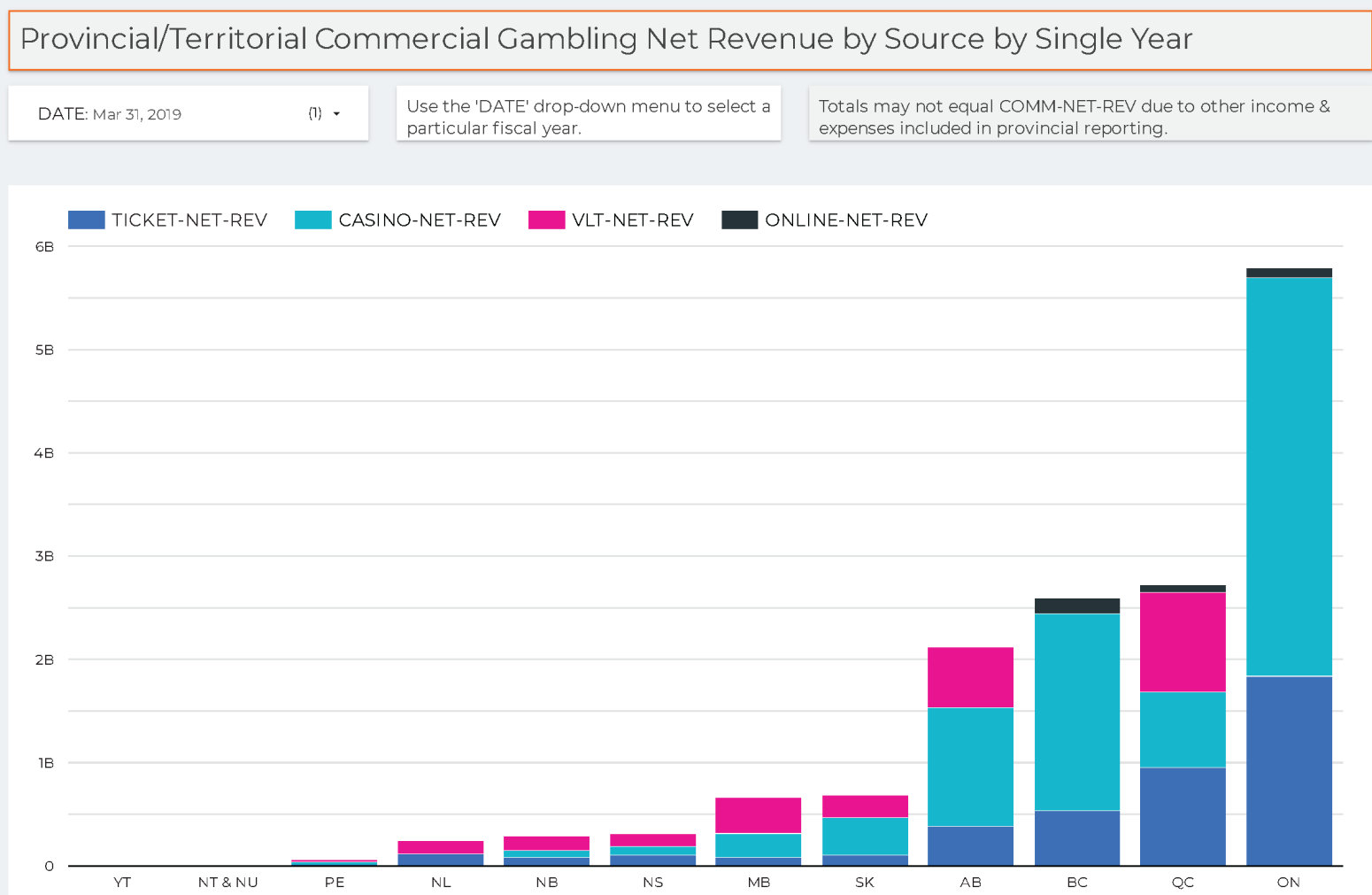

CASINO-NET-REV figure for ON from 2017/18+ excludes deduction of gaming service provider fees (making it comparable with previous years); Only ON, BC, QC separately report ONLINE-NET-REV; Figures for not available for all provinces / all time periods; CASINO-NET-REV figure for ON from $2017 / 18$ is for "Land Based Gaming" including gaming service provider fees to make figures comparable with earlier ones.

This interactive chart can be accessed from the Canadian Gambling Statistics (1970-2020) online database: NET-REV by Source by Yr by Prov. Use the DATE drop-down menu in the upper left to select a year or years of interest.

\section{Methods Employed for Documenting Canadian Gambling Statistics and Related Information}

Gambling in Canada is primarily a provincial responsibility ${ }^{4}$ which results in each of Canada's ten provinces and three territories designating organizations to operate legalized gambling in their jurisdictions. A natural place to turn, then, to locate figures about gambling revenue and net income is from annual reports and financial statements produced by these organizations. Approximately 850 reports from as far back as 1970 -- the beginning of Canada's modern gambling era -- were obtained and methodically reviewed ${ }^{5}$. Next, figures were extracted from the reports, added to spreadsheets and, where necessary, simple calculations were performed to ensure comparability between years and provinces. In some instances, details not included in reports were obtained directly from contacts at provincial organizations.

\footnotetext{
${ }^{4}$ With some exceptions. Horse racing, for example, is regulated by the Canadian Pari-Mutuel Agency (CPMA).

${ }^{5}$ Recent reports were located online while older reports from as far back as 1970 were located from print library collections or borrowed via interlibrary loan.
} 
Figure 5: Canada Casino Gambling Net Revenue by Province/Territory by Year

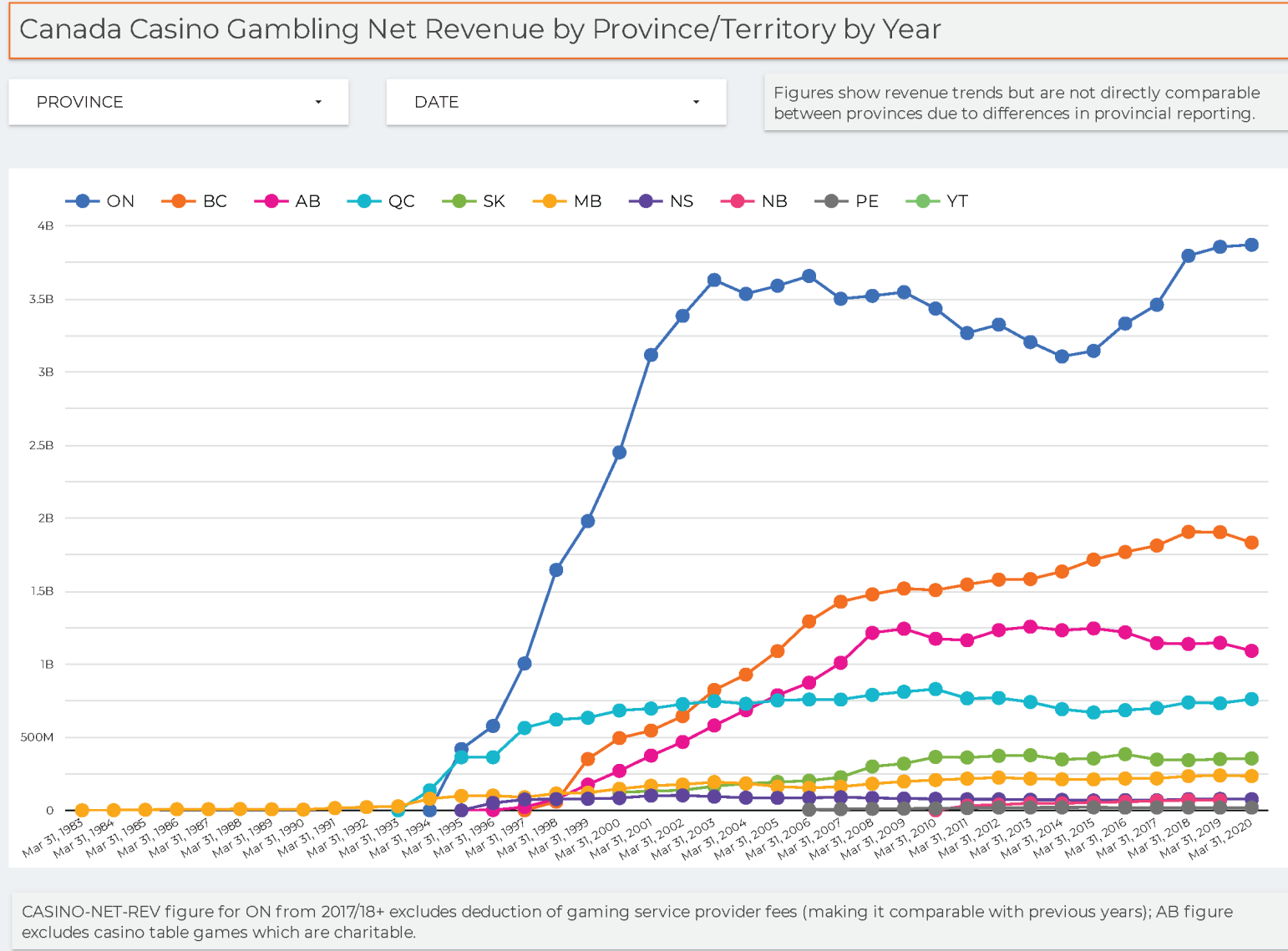

This interactive chart can be accessed from the Canadian Gambling Statistics (1970-2020) online database: CASINO-NET-REV by Prov [Line Chart]. Use the PROVINCE or DATE drop-down menu in the upper left to select a year or province of interest.

\section{The Challenges Involved in Locating Canadian Gambling Statistics and Related Information}

The process of extracting comparable figures from annual reports across jurisdictions is a more complicated task that it first appears. There are multiple reasons for this and they include:

1. Changes in Accounting Standards Over Time - The Canadian Accounting Standards Board (AcSB) requires publicly accountable enterprises to use International Financial Reporting Standards (IFRS) in the preparation of all interim and annual financial statements. ${ }^{6}$ These standards, required as of January, 2011 , have meant that provincial reporting of gambling revenue and expenses across provinces is now more similar than in the past. It also means that when IFRS standards are changed there are implications for how gambling revenue is reported. For example, when BCLC adopted IFRS 15 \& 9 in 2018-19, it

\footnotetext{
${ }^{6}$ Gov't of Canada https://www.canada.ca/en/revenue-agency/services/tax/businesses/topics/internationalfinancial-reporting-standards-ifrs.html
} 


\section{Critical Gambling Studies Blog}

meant that gambling revenue was presented net of prizes on their statement of comprehensive income. Ongoing changes make it difficult to accurately compare revenues over time.

2. Non-Standardized Terminology Used - A related issue is that there have been, over time, a variety of vocabularies used in provincial annual reports to indicate gambling revenues. For the purposes of my work, I defined revenue spent by gamblers as "gross revenue", revenue after prizes won as "net revenue", and revenue after both prizes won and expenses as "net income."

3. Reporting Category Differences - Some provinces combine two or more distinct gambling formats for reporting purposes while they're treated as separate entities in others. An example is online gambling which by its nature has elements of both casino gambling and lottery gambling depending on what a specific jurisdiction has permitted. Manitoba, unlike, B.C., Ontario and Quebec, does not distinguish between net revenue generated from their online casino and net revenue from land-based casinos.

4. Non-Timely Reporting - Most provinces publicly release annual financial reports within nine months or less from the end of the fiscal year. This means annual reports for a particular fiscal year (e.g., 2020-21) would normally be available by December of that year (i.e., Dec., 2021). Two provinces are routinely late in reporting by up to two years which causes delays in making Canada-wide comparisons using compiled statistics.

5. Unavailable Data - Provinces don't release figures for particular gambling formats at the same level of granularity or organize it in the same way. In some cases, data is unavailable or unreported (e.g., First Nations casino revenue in Quebec and Manitoba respectively).

6. Inclusion of Non-Gambling Revenues - Gambling revenue often needs to be disentangled from nongambling revenue when reporting agencies are also responsible for products such as alcohol and cannabis. This is the case in Alberta, Saskatchewan, and Manitoba. A similar situation exists when ancillary revenues (e.g., accommodations, parking, food \& beverage, etc.) are included or excluded in revenues and expenses.

7. Multiple Reporting Bodies - Provinces frequently have more than one agency responsible for reporting gambling revenue. Saskatchewan, for example, has five separate agencies that report for different gambling formats. These include WCLC (lotteries), Lotteries Trust Fund (lotteries), SaskGaming (casinos), SIGA (First Nation casinos), and SLGA (EGMs). Another complicating factor is that there are crossjurisdictional corporations in both Western Canada (WCLC) and Atlantic Canada (ALC) that operate lottery games for provinces and territories in these regions.

8. Errors Inputting Data - Lastly, there's a chance I have introduced errors inputting data or doing basic calculations to make figures comparable over time or between provinces. 
Figure 6: \# of Electronic Gambling Machines (EGMs) in Canada by Province by Year [2019]

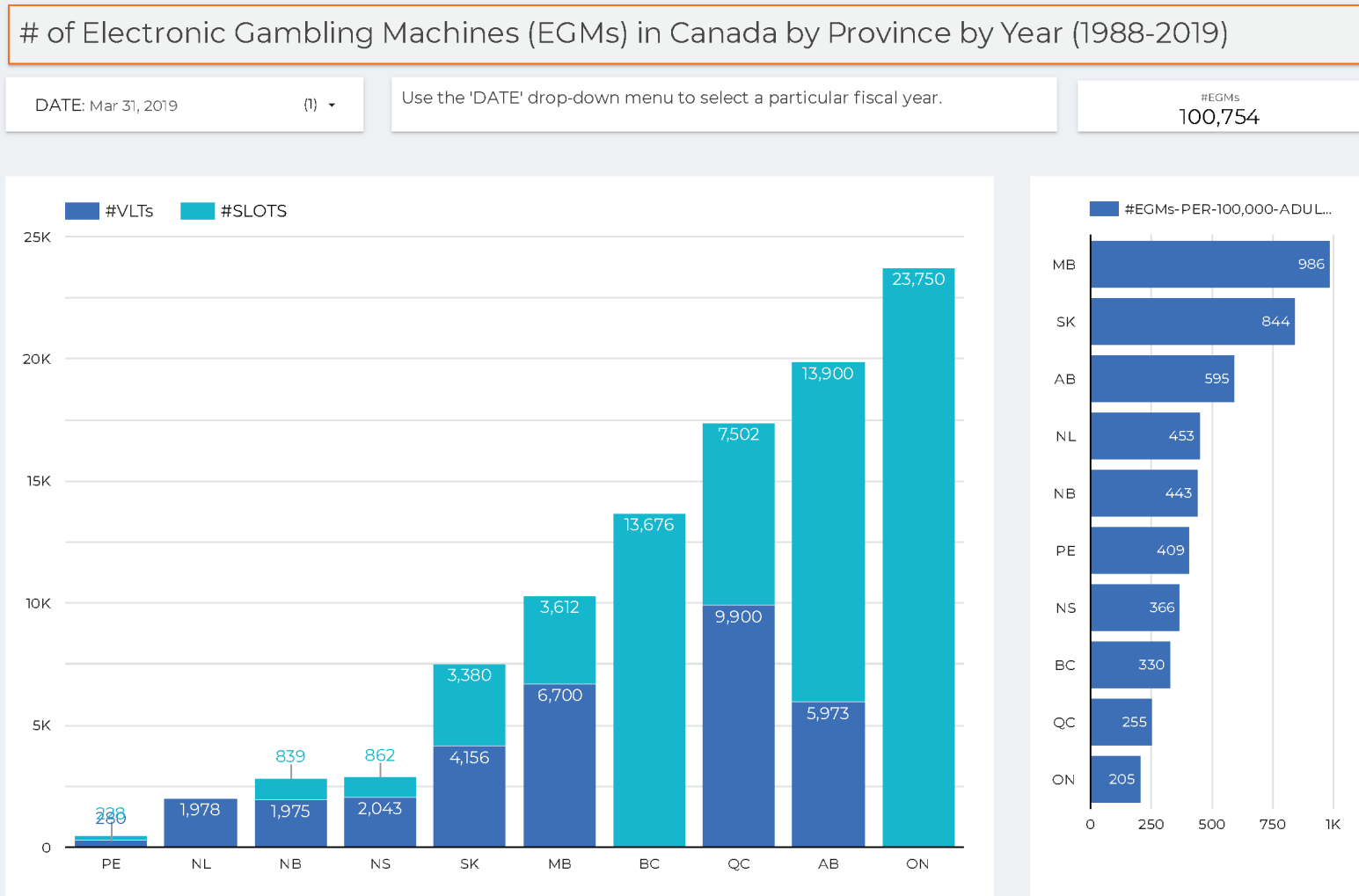

VLTs officially introduced: NB (1990/91), NL (1990/91), AB (1991/92), MB (1991/92), PE (1991/92), NS (1991/92), SK (1992/93), QC (1994/95). Some figures are estimated; Slot machines officially introduced: MB (1988/89), YT (1992/93), QC (1993/94), ON (1994/95), AB (1995/96), SK (1995/96), NS (1995/96), BC (1997/98), PE $(2005 / 06)$, NB (2010/11). Some figures prior to $2000 / 01$ estimated. Figures unavailable for VT.

This interactive chart can be accessed from the Canadian Gambling Statistics (1970-2020) online database: \#EGMS by Yr by Prov. Use the DATE drop-down menu in the upper left to select a year or years of interest.

Despite encountering a handful of challenges in the collection of gambling statistics, the Canadian Gambling Statistics (1970-2020) online database is useful for understanding trends in Canadian gambling over time. Charts and other visualizations illustrate how Canada's different gambling formats are stable, growing or declining across provinces and territories. The inclusion of information from the accompanying spreadsheets provides additional context for other factors (e.g., RG, events, etc.) that impact provincial commercial gambling revenues.

Go ahead and explore these materials to find out more about gambling in Canada!

Special thanks to all of the agencies and individuals that assisted in the collection of statistics.

Rhys Stevens is an academic librarian (Librarian III) at the University of Lethbridge in Lethbridge, Alberta. He supports the Alberta Gambling Research Institute as Librarian \& Information Specialist and also has subject liaison responsibilities for Geography, Maps \& Government Documents, Anthropology and Spatial/Numeric Data. He is currently a member of the Institute-funded research team undertaking a national study of gambling in Canada and has recently presented findings about Canadian gambling statistics at the Institute's 20th Annual Conference in April, 2021 [video / PDF]. 